\title{
Transformasi Indeks Vegetasi Citra LANDSAT 8 OLI untuk Pemetaan Musim Tanam pada Lahan Sawah di Kabupaten Buru, Provinsi Maluku
}

\author{
Vegeration Indeks Transformation of LANDSAT 8 OLI Image for Mapping the \\ Planting Season of Rice Fields in Buru Regency, Maluku Province
}

\author{
Nunung N. Tatisina ${ }^{1}$, Willem A. Siahaya ${ }^{2, *}$, Johanes P. Haumahu ${ }^{2}$ \\ ${ }^{1}$ Program Studi Agroekoteknologi, Jurusan Budidaya Pertanian, Fakultas Pertanian, Universitas Pattimura Jl. Ir. M. \\ Putuhena, Kampus Poka, Ambon 97233, Indonesia \\ ${ }^{2}$ Jurusan Budidaya Pertanian, Fakultas Pertanian, Universitas Pattimura Jl. Ir. M. Putuhena, Kampus Poka, Ambon \\ 97233, Indonesia \\ "Email Penulis Penulis Korespondensi: tonny_siahaya@yahoo.com
}

\begin{abstract}
The use of satellite imagery in agriculture has been widely used, for example in plantation areas or in rice fields. Satellite imagery can estimate the area of paddy fields and estimate rice production; however, the application of satellites for mapping the planting season in rice fields using Landsat 8 OLI imagery and NDVI (Normal Difference Vegetation Index) transformation has not been widely undertaken. This study aimed to analyze the growing season in paddy fields based on the results of NDVI analysis of Multitemporal Landsat 8 OLI imagery. Based on the results of research analyzed from the spectral value of NDVI images recorded in March and May 2020 then added with the results of observationsand farmer interviews in September 2020, it was found that there were color differences in NDVI images caused by differences in planting time or plant age at the time of recording the image. The planting season in rice fields in the Buru regency was generally two times per year or five times per two years. The increase in the rice planting season could be realized due to the availability of water in the field that was sufficient for the growth of rice plants, both from irrigation and rainfall. Based on the interpretation of the images used and field checks, it was found that the accuracy test results showed the overall accuracy of $88 \%$. The overall accuracy value is considered correct if it exceeds the tolerance limit given, which is $\geq 80 \%$.
\end{abstract}

Keywords: Buru Regency, growing season, Landsat 8, NDVI, paddy fields

\section{ABSTRAK}

Pemanfaatan citra satelit pada bidang pertanian telah banyak dilakukan, misalnya pada areal perkebunan ataupun pada areal persawahan. Citra satelit dapat menduga luas lahan sawah sampai dengan menduga produksi padi; tetapi pemanfaatan citra satelit untuk pemetaan musim tanam di lahan sawah menggunakan citra Landsat 8 OLI dan transformasi NDVI (Normalized Difference Vegetation Index) sampai saat ini belum banyak dilakukan. Penelitian ini bertujuan untuk Menganalisis musim tanam di lahan sawah berdasarkan hasil analisis NDVI Citra Landsat 8 OLI Multitemporal. Berdasarkan hasil penelitian yang dianalisis dari nilai spektral citra NDVI perekaman bulan Maret dan Mei tahun 2020 ditambah dengan hasil pengamatan serta wawancara petani pada bulan September 2020 didapatkan adanya perbedaan warna pada citra NDVI yang diakibatkan oleh perbedaan waktu tanam ataupun umur tanaman pada saat perekaman citra. Musimtanam pada lahan sawah di Kabupaten Buru umumnya dua kali per tahun atau lima kali per dua tahun. Peningkatan musim tanam padi dapat terealisasi karena ketersediaan air di lapangan untuk mencukupi pertumbuhan tanaman padi, baik yang bersumber dari air irigasi maupun curah hujan. Berdasarkan interpretasi citra yang digunakan dan pengecekan lapangan didapatkan bahwa hasil uji akurasi menunjukkan hasil overall accuracy sebesar $88 \%$. Nilai overall accuracy dianggap benar jika melebihi batas toleransi yang diberikan yakni $\geq 80 \%$.

Kata kunci: Kabupaten Buru, Landsat 8, lahan sawah, musim tanam, NDVI

\section{PENDAHULUAN}

Lahan sawah merupakan lahan yang digunakan untuk budidaya tanaman padi yang digenangi baik secara terus-menerus sepanjang tahun maupun bergiliran dengan tanaman palawija. Segala macam jenis tanah dapat dijadikan lahan sawah asalkan air cukup
tersedia(Hardjowigeno et al., 2004).

Daerah kepulauan yang didominasi pulau kecil memiliki luas lahan yang sempit sehingga kawasan pengembangan pertanian lahan sawahnya terbatas. Misalnya di Provinsi Maluku dengan luasan daratan $10 \%$, lahan sawah hanya ditemukan di Pulau Seram dan Pulau Buru. 
Berdasarkan data BPS Provinsi Maluku (2019) luas panen lahan sawah sebesar $23.317 \mathrm{Ha}$ dan produksinya mencapai 90.892 ton. Kurang lebih 60\% (54.427 ton) produksi padi berasal dari Pulau Buru. Penetapan Pulau Buru sebagai lumbung padi di Provinsi Maluku oleh Presiden (2015) mewajibkan pemerintah dan pihak terkait untuk menjaga dan mempertahankan produktivitas padi agar tetap stabil dan cenderung meningkat. Salah satu cara yang dapat dilakukan adalah dengan melakukan pemantauan terhadap kondisi pertanaman padi sawah.

Tanaman padi merupakan tanaman pangan unggulan karena lebih dari $90 \%$ penduduk Indonesia mengkonsumsi beras sebagai makanan pokok. Hal tersebut menyebabkan tanaman padi mendapat perhatian khusus, karena menyangkut masalah stabilitas sosial, ekonomi serta politik (Hafizh et al., 2013). Permasalahan penyediaan pangan nasional dapat disebabkan, antara lain karena pengurangan luas lahan sawah, bencana alam (banjir, kekeringan) yang menyebabkan gagal panen, dan salah musim dalam awal pengolahan (Murdiyati dan Danoedoro, 2010).

Musim tanam dapat menjadi salah satu cara meningkatkan ketahanan pangan karena dapat meningkatkan produksi melalui perluasan areal tanam/panen dengan meningkatkan frekuensi tanam per tahun, disesuaikan dengan ketersediaan air (Makarim et al., 2005 dalam Makarim et al., 2017). Musim tanam dapat didefinisikan sebagai pengaturan waktu pertanaman pada suatu komoditas terpilih yang diusahakan pada sebidang lahan dalam kurun waktu tertentu (biasanya satu tahun). Musim tanam di daerah tropis biasanya disusun selama satu tahun dengan memperhatikan curah hujan, terutama pada lahan sawah yang memerlukan air untuk pertumbuhan tanaman padi.

Kini musim musim tanam semakin penting untuk ditingkatkan mengingat besarnya dampak perubahan iklim, khususnya perubahan pola curah hujan. Apriyana dan Kailaku (2015) dalam Makarim et al. (2017) menggambarkan bahwa terjadinya perubahan pola curah hujan di beberapa lokasi di Jawa telah mengubah waktu tanam padi sawah dan berkurangnya areal tanam, selain menurunnya produktivitas. Dengan penyesuaian waktu tanam, pemilihan komoditas, kondisi iklim pada awal serta selama musim tanam dipertimbangkan, menjadi salah satu cara untuk menghindari gagal tanam dan gagal panen akibat kekeringan atau banjir. Untuk memantau musim tanam pada lahan sawah dengan luasan yang besar maka, dapat digunakan berbagai metode (teknologi). Metode yang biasanya digunakan seperti survei lapangan (observasi), angket (kuesioner), wawancara, studi dokumen, analisis SIG serta teknologi Penginderaan Jauh.

Penginderaan jauh merupakan salah satu metode yang dapat digunakan untuk memantau lahan pertanian dengan efisien dan efektif. Penginderaan jauh telah diakui sebagai alat yang ampuh dan efektif dalam mendeteksi penggunaan lahan dan perubahan penutup lahan (Ardiansyah et al., 2015). Kelebihan teknologi ini adalah dapat meliput wilayah yang luas, lebih ekonomis, dan mempunyai akurasi yang baik karena teknologi ini dapat menyadap objek permukaan lahan secara detail pada citra resolusi tinggi (Wahyuntoet al., 2006 dalam Avicienna et al., 2012). Pemanfaatan citra satelit pada bidang pertanian telah banyak dilakukan, misalnya pada areal perkebunan ataupun pada areal persawahan untuk menduga luas lahan ataupun hasil produksi. Dalam peranannya memberikan informasi, ada berbagai macam metode yang dapat digunakan untuk mengolah data citra penginderaan jauh seperti Penisbahan Saluran, Pengurangan Saluran, Rotasi Citra dan Analisis Komponen Utama, Transformasi Kauth dan Thomas, serta Indeks Vegetasi.

Indeks Vegetasi merupakan suatu algoritma yang diterapkan terhadap citra (biasanya multispektral), untuk menonjolkan aspek kerapatan vegetasi ataupun aspek lain yang berkaitan dengan kerapatan, misalnya biomassa, leaf area index (LAI), konsentrasi klorofil (Danoedoro, 2012 dalam Siahaya, 2016). Indeks vegetasi dapat digunakan untuk menganalisis kerapatan vegetasi yang selanjutnya dapat dimanfaatkan untuk memantau musim tanam, salah satu transformasinya adalah NDVI.

NDVI adalah modulasi rasio dari kanal inframerah dekat (near infrared) dan kanal merah (red). NDVI merupakan metode standar yang biasanya digunakan dalam membandingkan tingkat kehijauan vegetasi (Danoedoro, 2012 dalam Ardiansyah et al., 2015). Vegetasi yang aktif melakukan fotosintesis akan menyerap sebagian besar gelombang merah sinar matahari dan memantulkan gelombang inframerah dekat lebih tinggi, vegetasi yang tingkat klorofilnya rendah atau kurang sehat akan lebih banyak memantulkan gelombang merah dan akan menyerap lebih banyak gelombang inframerah dekat (Prasetyo et al., 2017). NDVI merupakan parameter biofisik yang berkorelasi dengan aktivitas fotositesis serta dapat memberikan informasi tentang perubahan dinamis dari vegetasi tertentu (Xie et al., 2008). NDVI Dapat dipakai untuk mendapatkan informasi tentang pertanaman seperti kurva pertumbuhan tanaman, penutup lahan, kerusakan tanaman akibat penyakit. Tinggi rendahnya suatu kerapatan vegetasi dapat diketahui dengan metode ini.

Satelit Landsat 8 OLI merupakan salah satu wahana penginderaan jauh yang datanya terbuka untuk umum dan dapat diunduh secara gratis (Loveland and Irons, 2016). Satelit Landsat memiliki resolusi temporal 16 hari serta resolusi spasial $30 \mathrm{~m}^{2}$. Indeks Vegetasi dari citra satelit multitemporal dapat digunakan untuk memetakan musim tanam di lahan sawah dengan melihat tinggi rendahnya kerapatan vegetasi pada jangka waktu tertentu.

Berdasarkan uraian di atas maka dilakukan penelitian yang bertujuan untuk memetakan musim tanam berdasarkan tingkat kerapatan vegetasi yang dianalisis dari citra satelit Landsat 8 OLI dengan menggunakan metode transformasi Normalized Difference Vegetation Index (NDVI) di Kabupaten Buru, Provinsi Maluku. 


\section{BAHAN DAN METODE}

\section{Tempat dan Waktu Penelitian}

Penelitian lapangan sudah dilaksanakan di lahan sawah Kabupaten Buru, Provinsi Maluku pada bulan September 2020.

\section{Bahan dan Alat}

Bahan yang digunakan pada penelitian ini adalah data citra satelit Landsat 8 (OLI) Path/Row 110/62 Multitemporal perekaman tahun 2020; Peta Rupa Bumi Indonesia (RBI) digital skala 1: 50.000 lembar Pulau Buru (Bakosurtanal, 2018); Peta Lahan Sawah (citra satelit ESRI dan citra Google Earth); dan data iklim. Peralatan yang digunakan dalam penelitian ini adalah alat tulis, Global Positioning System (GPS), Kamera, laptop, dan perangkat lunak (software) yang digunakan sebagai sarana pengolahan dan interpretasi citra seperti yang disajikan pada Tabel 1.

Tabel 1. Software yang digunakan

\begin{tabular}{|c|c|c|}
\hline No & Software & Fungsi \\
\hline \multirow[t]{2}{*}{1} & ENVI 5.1 & $\begin{array}{l}\text { Koreksi Radiometrik, Koreksi } \\
\text { Geometrik, }\end{array}$ \\
\hline & & $\begin{array}{l}\text { Pemotongan Citra dan Analisis } \\
\text { NDVI }\end{array}$ \\
\hline 2 & ArcGis 10.3 & $\begin{array}{l}\text { Pembuatan Peta batas lahan } \\
\text { sawah dan Layout } \\
\text { peta }\end{array}$ \\
\hline 3 & $\begin{array}{l}\text { Microsoft } \\
\text { Office } 2016\end{array}$ & Pengolahan data \\
\hline
\end{tabular}

\section{Desain dan Prosedur Penelitian}

Tahap-tahap desain dan prosedur penelitian adalah sebagaimana digambarkan secara skematik pada Gambar 1.

\section{Pre-Processing Citra Landsat}

\section{Koreksi radiometrik}

Koreksi Radiometrik bertujuan untuk memperbaiki kualitas visual citra sekaligus memperbaiki nilainilai piksel yang tidak sesuai dengan nilai pantulan yang sebenarnya karena hambatan atmosfer. Metode yang paling sederhana yang dapat digunakan adalah metode Dark Object Subtraction (DOS) dengan persamaannya adalah:

$$
\mathrm{Y} \text { koreksi }=\mathrm{Y}-\mathrm{Y} \min
$$

Keterangan: $Y=$ Nilai spektral setiap piksel

\section{Koreksi Geometrik}

Koreksi geometrik dilakukan untuk rektifikasi (pembetulan) agar koordinat pada citra sesuai dengan koordinat geografi. Koreksi geometrik perlu dilakukan agar nilai piksel yang sebenarnya berada pada posisi yang tepat. Koreksi geometrik menggunakan Metode non parametrik atau Transformasi berdasarkan GCP merupakan metode yang memerlukan Ground Control Point (GCP), yakni titik-titik yang telah diketahui posisinya dalam sistem koordinat geografis ataupun dalam sistem koordinat peta (Djurdjani dan Kartini, 2004). Formula dalam Koreksi Geometrik untuk penggunaan GCP menggunakan persamaan sebagai berikut:

$\mathrm{X}=\mathrm{f} 1(\mathrm{X}, \mathrm{Y})$

$\mathrm{Y}=\mathrm{f} 2(\mathrm{X}, \mathrm{Y})$

Keterangan: $\mathrm{x}, \mathrm{y}=$ Koordinat lama citra (kolom baris);

$\mathrm{X}, \mathrm{Y}=$ Koordinat sebenarnya (sistem koordinat peta);

f1, f2 = Fungsi Transformasi

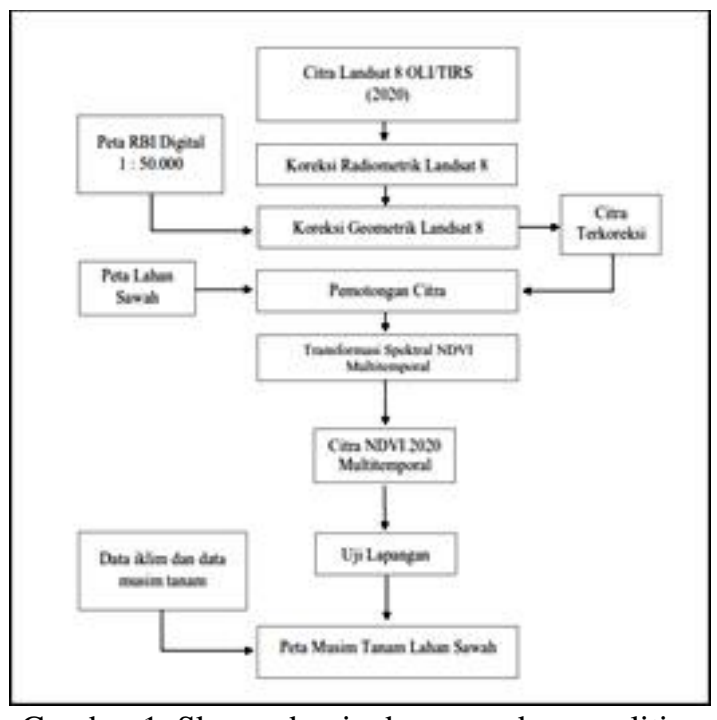

Gambar 1. Skema desain dan prosedur penelitian

\section{Pemotongan Citra}

Pemotongan citra merupakan suatu proses pemotongan pada citra yang akan digunakan agar sesuai dengan lokasi penelitian. Pemotongan citra dilakukan untuk mempercepat proses analisis dan memperkecil ukuran ruang penyimpanan citra pada hardware. Layer batas untuk memotong citra menggunakan peta batas lahan sawah yang dibuat dengan cara menginterpretasi citra satelit ESRI dan citra Google Earth.

\section{Transformasi Indeks Vegetasi}

Transformasi indeks vegetasi dilakukan untuk mengetahui tingkat kerapatan vegetasi. NDVI merupakan metode standar yang digunakan untuk membandingkan tingkat kehijauan vegetasi yang berasal dari citra satelit. Analisis nilai kerapatan dilakukan dengan menggunakan transformasi indeks vegetasi NDVI.

$$
\text { NDVI } \quad=\frac{N I R-R E D}{N I R+R E D}
$$

Keterangan: NIR = band inframerah dekat $($ Near Infrared $;$ RED = band merah $($ Red $)$ 


\section{Uji Akurasi}

Uji ketelitian dilakukan dilakukan untuk menguji kebenaran dari hasil interpretasi yang diperoleh dengan cara pengecekan lapangan pada beberapa titik sampel yang dipilih dari setiap penutup/penggunaan lahan yang homogen. Besarnya tingkat akurasi diperoleh dari hasil uji akurasi, dihitung dari matriks analisis akurasi dengan menggunakan persamaan berikut:

Producer's accuracy $=\mathrm{Xii} / \mathrm{X}+1$

User's accuracy $=X i i / X i$ x 100\%

Kappa accuracy $=\frac{\sum_{k}^{r} \mathrm{X} k k-\sum_{k}^{r} \mathrm{Xkt} \mathrm{Xtk}}{1-\sum_{k}^{r} \mathrm{Xkt} \mathrm{Xtk}}$

Overall accuracy $=\sum$ Xii $\times 100$

Keterangan: $\mathrm{N}=$ Jumlah semua piksel yang digunakan untuk pengamatan; $\mathrm{R}=$ Jumlah baris/lajur pada matriks kesalahan (jumlah kelas); Xkk = Jumlah piksel pada kelas bersangkutan (diagonal matriks); Xkt $=\Sigma \mathrm{Xij}$ (jumlah semua kolom pada baris ke i); Xtk $=\Sigma X i j$ (jumlah semua kolom pada lajur ke j)

\section{HASIL DAN PEMBAHASAN}

\section{Pra Pengolahan Citra (Pre-Processing)}

Pada tahap pra pengolahan citra dilakukan beberapa koreksi yang bertujuan memperbaiki kualitas citra agar citra yang digunakan dapat memberikan informasi yang akurat. Tahap pra pengolahan citra pada penelitian ini meliputi koreksi radiometrik, koreksi geometrik. Citra yang digunakan dalam penelitian ini adalah citra Landsat 8 OLI tahun perekaman 2020.

\section{Koreksi radiometrik}

Koreksi Radiometrik merupakan suatu upaya agar citra yang digunakan benar-benar memberikan informasi yang akurat. Gambar 1 menunjukkan perbandingan antara citra yang belum dikoreksi radiometrik dan citra hasil koreksi radiometrik.

\section{Koreksi Geometrik}

Koreksi geometrik dilakukan untuk rektifikasi sehingga diperoleh citra dengan proyeksi dan koordinat yang akurat. Gambar 3 menunjukkan perbandingan antara citra yang belum dikoreksi radiometrik dan citra hasil koreksi radiometrik.

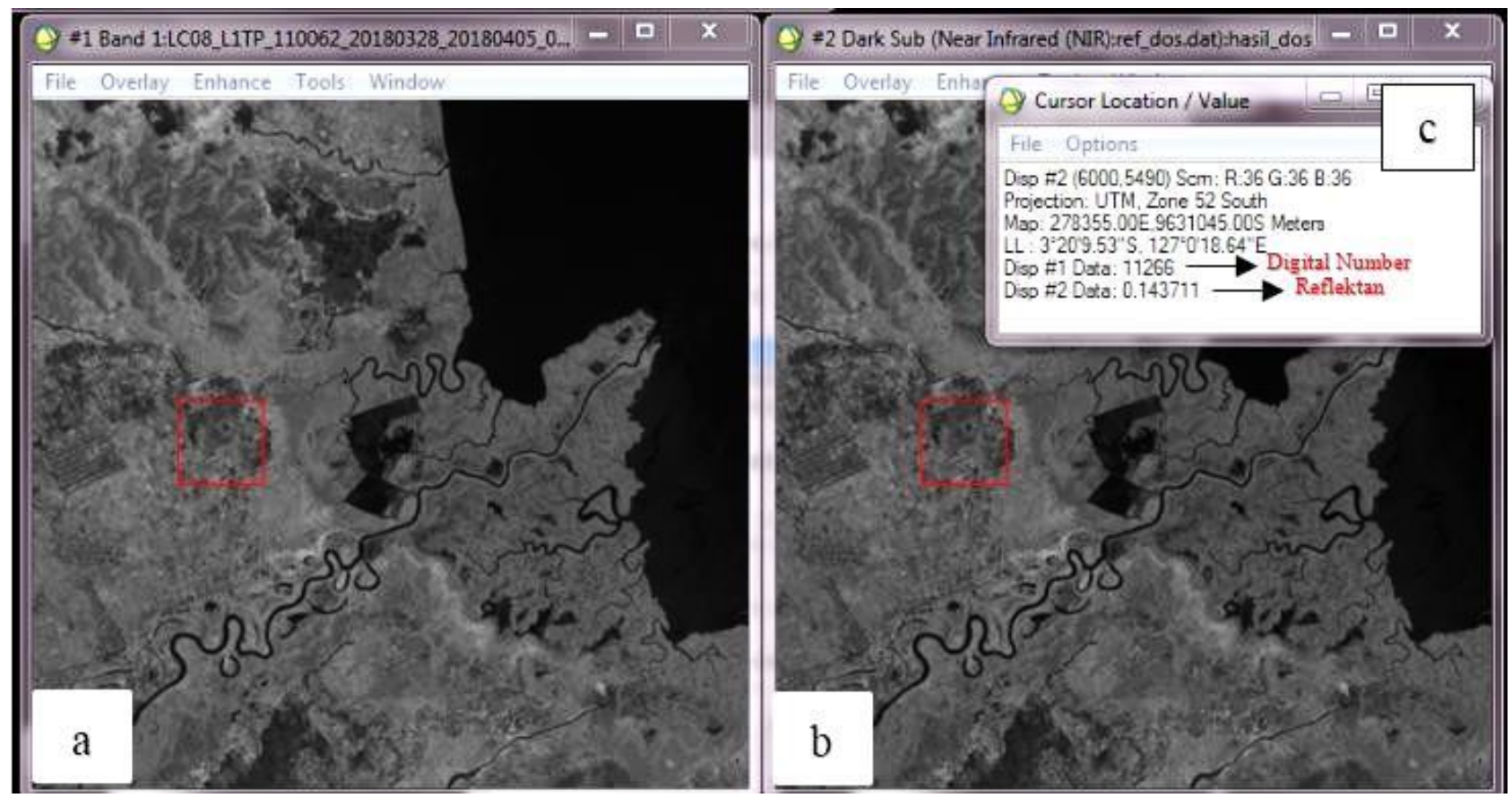

Gambar 2. Gambar digital number dan hasil koreksi radiometrik; a) digital number; b) reflektan; c) nilai digital number dan nilai reflektan 


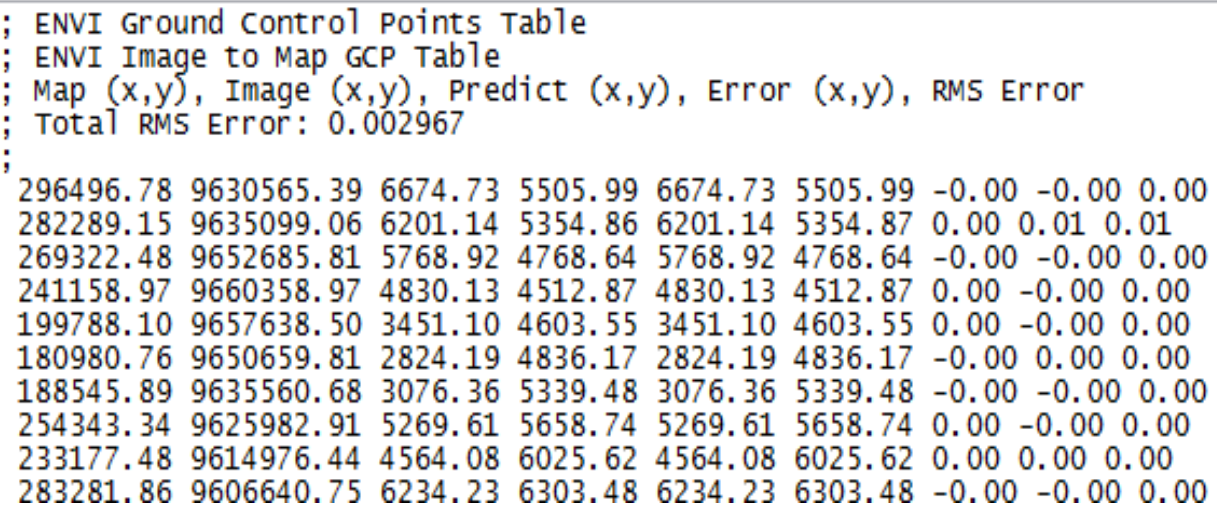

Gambar 3. Nilai RMS error Citra Landsat 8 OLI bulan Mei 2020 (hasil analisis Citra Landsat 8 OLI)

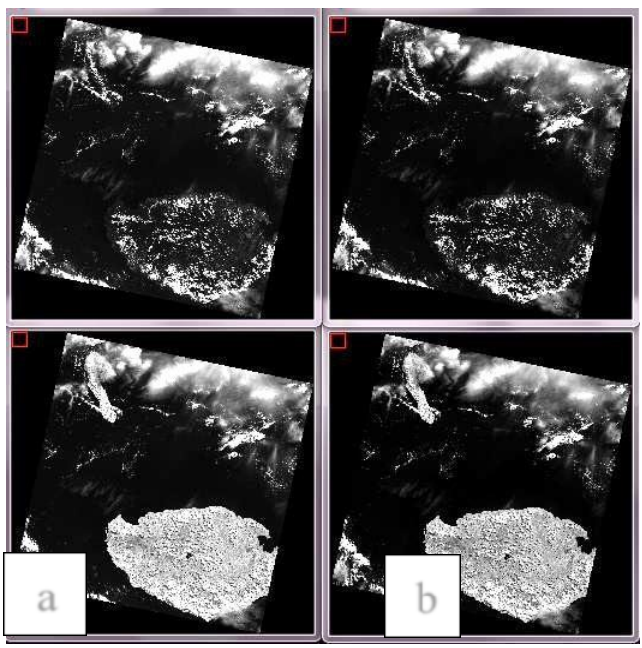

Gambar 4. Citra Landsat 8 OLI Tahun 2020 Band 4 \& 5; a) Belum dikoreksi Geometrik; b) Sudah dikoreksi Geometrik

\section{Pengolahan Citra}

Tahap pengolahan citra merupakan kegiatan analisis digital citra satelit. Pengolahan citra bertujuan untuk mendapatkan data dan informasi dengan berbagai jenis metode yang sesuai dengan kebutuhan penelitian. Dalam penelitian ini menggunakan metode Indeks Vegetasi yakni Transformasi Normalized Difference Vegetation Index (NDVI).

\section{Transformasi NDVI}

Indeks vegetasi merupakan salah satu nilai yang memiliki interval tertentu dimana nilai tersebut mempresentasikan tingkat kehijauan vegetasi (Ardiansyah, 2015 dalam Ardiansyah et al., 2015). Nilai statistika indeks vegetasi lahan sawah Kabupaten Buru dapat dilihat pada Tabel 2.

Tabel 2. Nilai Statistik Hasil Transformasi NDVI

\begin{tabular}{lccc}
\hline \multicolumn{1}{c}{ Bulan } & Minimal & Maksimal & Rata-rata \\
\hline 1 Maret 2020 & -0.072801 & 0.822527 & 0.584192 \\
20 Mei 2020 & -0.262725 & 0.860534 & 0.523079 \\
\hline
\end{tabular}

Sumber: Hasil analisis citra Landsat 8 OLI
Pola Indeks Vegetasi Lahan Sawah

Pola indeks vegetasi dalam penelitian ini ditentukan berdasarkan nilai indeks vegetasi hasil transformasi NDVI, dan nilai indeks vegetasi hasil pengamatan lapangan. Nilai indeks hasil pengamatan lapangan ditentukan berdasarkan fase pertumbuhan padi di lahan sawah yang diperoleh pada saat observasi dan uji lapangan. Fase pertumbuhan padi diperoleh melalui wawancara baik dengan petani, ketua kelompok tani maupun ketua gabungan kelompok tani.

Lahan sawah di Kabupaten Buru terdapat pada tiga Kecamatan yakni Kecamatan Waeapo, Kecamatan Waelata dan Kecamatan Lolong Guba.

1. Kecamatan Waeapo

Penentuan nilai indeks dapat digunakan untuk mengetahui pola indeks vegetasi lahan sawah di Kecamatan Waeapo. Nilai indeks yang dikombinasikan dengan data dari wawancara dengan petani dapat digunakan sebagai acuan untuk penentuan fase pertumbuhan padi di lahan sawah. Berdasarkan nilai indeks yang diketahui dapat membentuk pola indeks vegetasi. Nilai indeks vegetasi lahan sawah berdasarkan hasil analisis citra dapat dilihat pada Tabel 3 dan pola indeks pertumbuhan padi di lahan sawah yang disandingkan dengan hasil wawancara dengan petani disajikan pada Gambar 4.

Tabel 3. Nilai indeks vegetasi lahan sawah Kecamatan Waeapo tahun 2020

\begin{tabular}{ccc|cc}
\hline No & \multicolumn{2}{c|}{ Koordinat } & \multicolumn{2}{c}{ Nilai Indeks } \\
\cline { 2 - 5 } & $\mathrm{X}$ & $\mathrm{Y}$ & $01 / 03 / 2020$ & $20 / 05 / 2020$ \\
\hline 1 & 279948.00 & 9634819.00 & 0.371449 & 0.801901 \\
2 & 279889.00 & 9634696.00 & 0.548592 & 0.793183 \\
3 & 279948.00 & 9634819.00 & 0.371449 & 0.801901 \\
4 & 275515.00 & 9628114.00 & 0.504687 & 0.120537 \\
5 & 275515.00 & 9628114.00 & 0.504687 & 0.120537 \\
6 & 273409.00 & 9629337.00 & 0.729868 & 0.205431 \\
7 & 273409.00 & 9629337.00 & 0.729868 & 0.205431 \\
\hline
\end{tabular}

Sumber: Hasil analisis citra Landsat 8 OLI multitemporal 


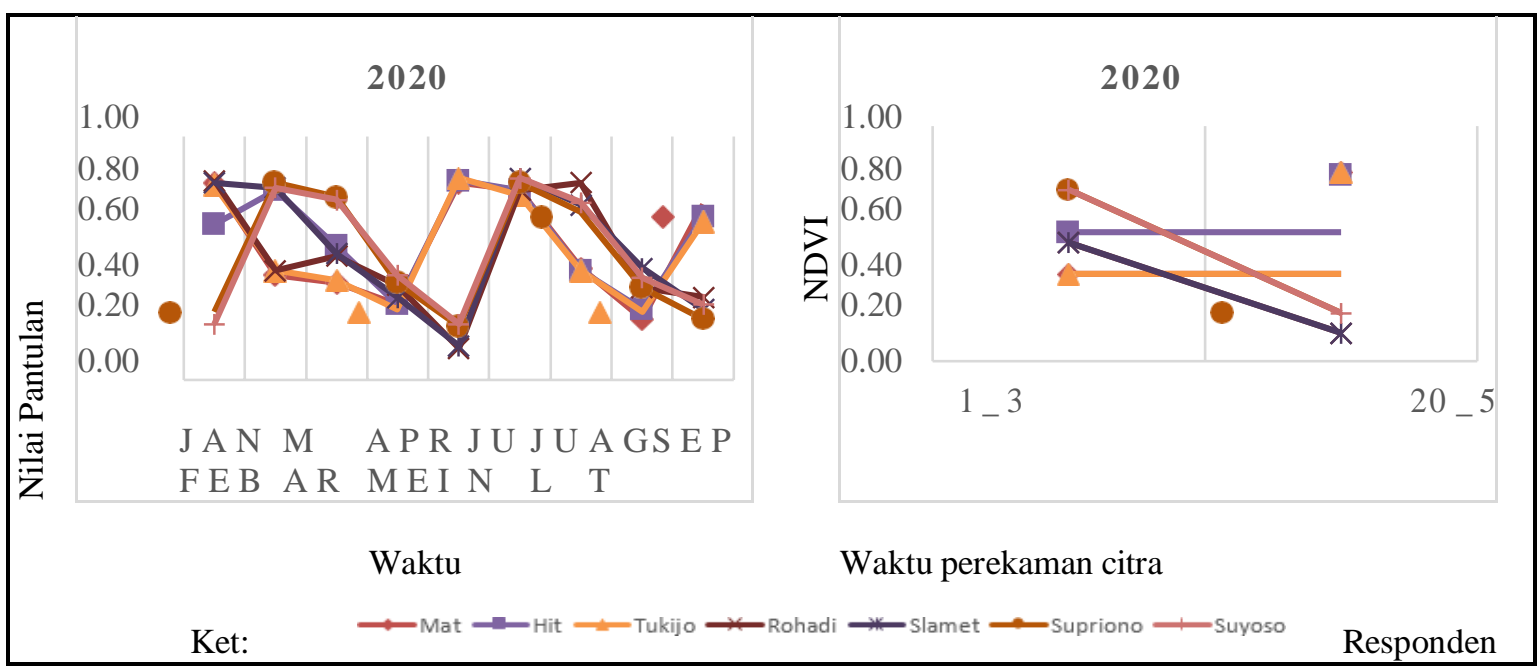

Gambar 5. Grafik pola indeks vegetasi di lahan sawah Tahun 2020; a) Grafik pola tanam hasil pengamatan; b) Grafik Pola Indeks vegetasi di lahan sawah

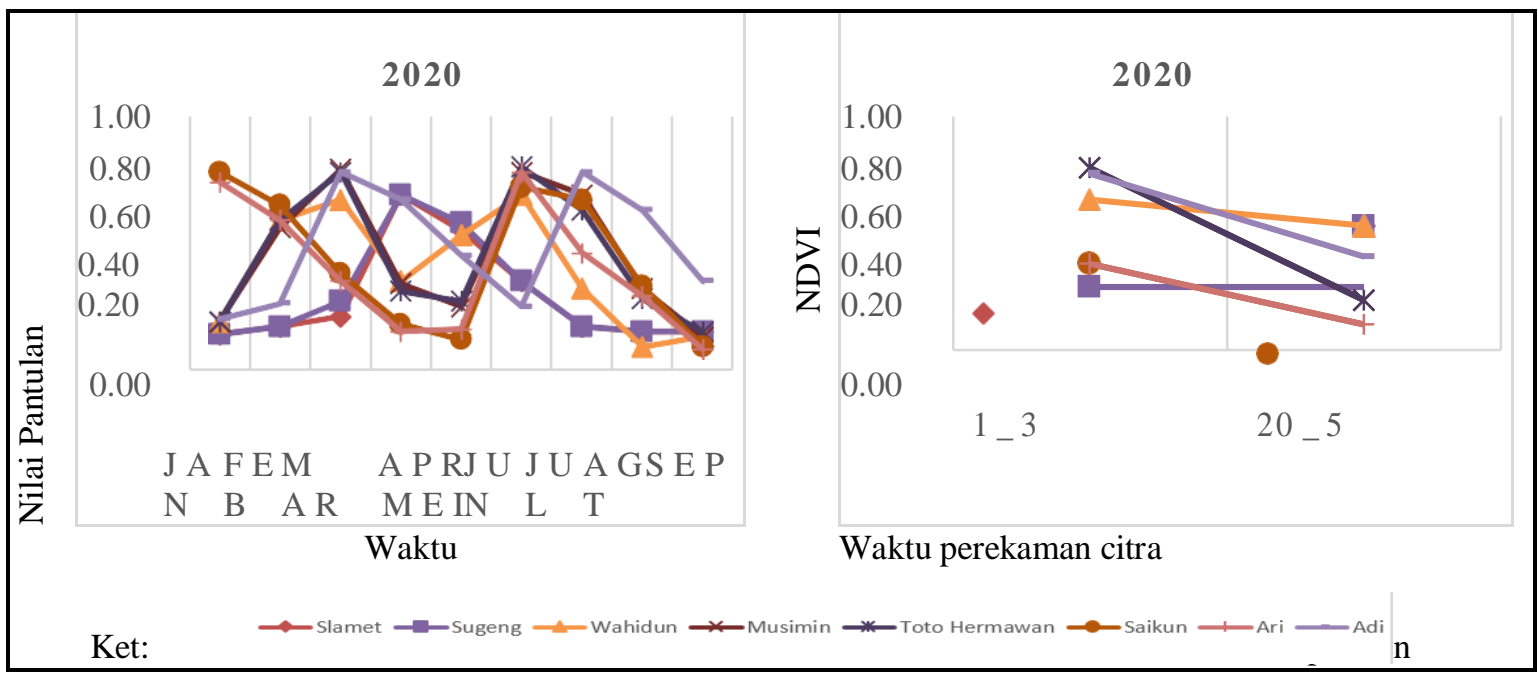

Gambar 6. Grafik pola indeks vegetasi di lahan sawah tahun 2020; a) grafik pola tanam hasil pengamatan; b) grafik pola indeks vegetasi di lahan sawah

Tabel 4. Nilai indeks vegetasi lahan sawah di Kecamatan Waelata Tahun 2020.

\begin{tabular}{ccccc}
\hline \multirow{2}{*}{ No } & \multicolumn{2}{c}{ Koordinat } & \multicolumn{2}{c}{ Nilai Indeks } \\
\cline { 2 - 5 } & $\mathrm{X}$ & $\mathrm{Y}$ & $01 / 03 / 2020$ & $20 / 05 / 2020$ \\
\hline 1 & 269071.00 & 9614248.00 & 0.270383 & 0.532022 \\
2 & 269071.00 & 9614248.00 & 0.270383 & 0.532022 \\
3 & 273217.00 & 9620481.00 & 0.644627 & 0.532905 \\
4 & 278992.00 & 9622028.00 & 0.779646 & 0.214098 \\
5 & 278992.00 & 9622028.00 & 0.779646 & 0.214098 \\
6 & 279511.00 & 9622885.00 & 0.369039 & 0.109674 \\
7 & 279511.00 & 9622885.00 & 0.369039 & 0.109674 \\
8 & 278894.00 & 9622517.00 & 0.755368 & 0.400659 \\
\hline
\end{tabular}

Sumber: Hasil analisis citra Landsat 8 OLI multitemporal

Berdasarkan grafik pola indeks vegetasi di atas dapat diketahui jika nilai pantulan serta nilai NDVI merupakan nilai acuan untuk menentukan fase yang terjadi pada tanaman padi di lahan sawah. Indeks vegetasi dengan nilai tinggi menggambarkan tingkat kehijauan daun yang tinggi sedangkan indeks vegetasi dengan nilai rendah menggambarkan tingkat kehijauan daun yang rendah di lapangan.

2. Kecamatan Waelata

Penentuan nilai indeks dapat digunakan untuk mengetahui pola indeks vegetasi lahan sawah di Kecamatan Waelata. Nilai indeks yang dikombinasikan dengan data dari wawancara dengan petani dapat digunakan sebagai acuan untuk penentuan fase pertumbuhan padi di lahan sawah. Berdasarkan nilai indeks yang diketahui dapat membentuk pola indeks vegetasi. Nilai indeks vegetasi lahan sawah berdasarkan hasil analisis citra dapat dilihat pada Tabel 4 dan pola indeks pertumbuhan padi di lahan sawah yang disandingkan dengan hasil wawancara dengan petani disajikan pada Gambar 5. 
Berdasarkan grafik pola indeks vegetasi di atas dapat diketahui jika nilai pantulan sertanilai NDVI merupakan nilai acuan untuk menentukan fase yang terjadi pada tanaman padi di lahan sawah. Indeks vegetasi dengan nilai tinggi menggambarkan tingkat kehijauan daunyang tinggi sedangkan indeks vegetasi dengan nilai rendah menggambarkan tingkat kehijauan daun yang rendah di lapangan.

3. Kecamatan Lolong Guba

Penentuan nilai indeks dapat digunakan untuk mengetahui pola indeks vegetasi lahan sawah di Kecamatan Lolong Guba. Nilai indeks yang dikombinasikan dengan data dari wawancara dengan petani dapat digunakan sebagai acuan untuk penentuan fase pertumbuhan padi di lahan sawah. Berdasarkan nilai indeks yang diketahui dapat membentuk pola indeks vegetasi. Nilai indeks vegetasi lahan sawah berdasarkan hasil analisis citra dapat dilihat pada Tabel 4.5 dan pola indeks pertumbuhan padi di lahan sawah yang disandingkan dengan hasil wawancara dengan petani disajikan pada Gambar 6.

Berdasarkan Gambar 6, jika nilai pantulan sertanilai NDVI merupakan nilai acuan untuk menentukan fase yang terjadi pada tanaman padi di lahan sawah. Indeks vegetasi dengan nilai tinggi menggambarkan tingkat kehijauan daun yang tinggi, sedangkan indeks vegetasi dengan nilai rendah menggambarkan tingkat kehijauan daun yang rendah di lapangan.

\section{Sebaran Nilai Indeks Vegetasi}

Berdasarkan hasil analisis citra menggunakan transformasi NDVI diperoleh perbedaan nilai indeks vegetasi pada masing-masing citra yang digunakan. Perbedaan nilai- nilai indeks tersebut kemudian diklasifikasikan agar dapat memberikan informasi yang lebih jelas dan mudah dipahami. Tabel 6 menampilkan rentang klasifikasi kerapatan vegetasi yang diperoleh dari pengelompokan nilai NDVI.

Tabel 5. Nilai indeks vegetasi lahan sawah Kecamatan Lolong Guba, 2020.

\begin{tabular}{ccccc}
\hline \multirow{2}{*}{ No } & \multicolumn{2}{c}{ Koordinat } & \multicolumn{2}{c}{ Nilai Indeks } \\
\cline { 2 - 5 } & X & Y & $01 / 03 / 2020$ & $20 / 05 / 2020$ \\
\hline 1 & 267098.00 & 9615713.00 & 0.160688 & 0.680496 \\
2 & 267098.00 & 9615713.00 & 0.160688 & 0.680496 \\
3 & 267965.00 & 9617496.00 & 0.527411 & 0.299497 \\
4 & 268279.00 & 9618195.00 & 0.707167 & 0.342100 \\
5 & 268061.00 & 9622898.00 & 0.668878 & 0.760899 \\
6 & 268373.00 & 9623242.00 & 0.680557 & 0.713491 \\
7 & 271139.00 & 9623490.00 & 0.404073 & 0.453720 \\
8 & 270228.00 & 9622631.00 & 0.599977 & 0.231840 \\
\hline
\end{tabular}

Sumber: Hasil analisis citra Landsat 8 OLI multitemporal

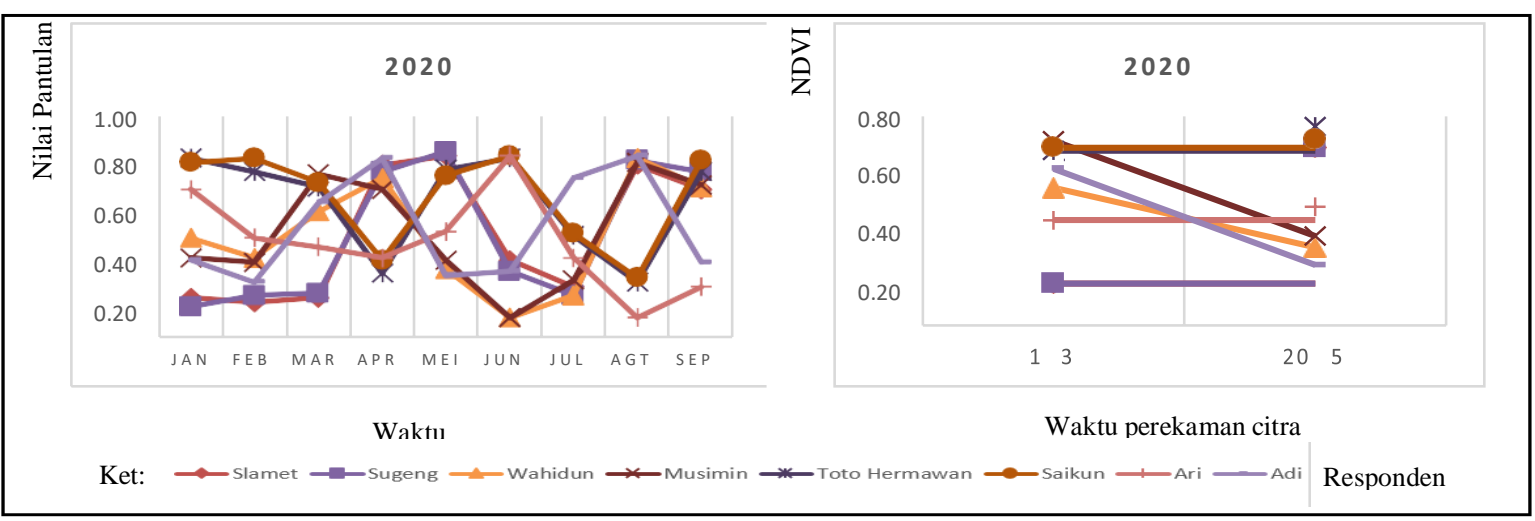

Gambar 7. Grafik pola indeks vegetasi di lahan sawah tahun 2020; a) grafik pola tanam hasil hasil pengamatan, b) grafik pola Indeks vegetasi di lahan sawah

Tabel 6. Rentang klasifikasi kerapatan vegetasi

\begin{tabular}{clll}
\hline No & Nilai Indeks & \multicolumn{1}{c}{ Kelas } & \multicolumn{1}{c}{ Objek } \\
\hline 1 & $-1.00-0.15$ & Non Vegetasi & Awan, Badan air, Tanah terbuka \\
2 & $0.15-0.30$ & Vegetasi Jarang & Pemukiman, Lahan kosong \\
3 & $0.30-0.55$ & Vegetasi Sedang & Sawah \\
4 & $0.55-0.80$ & Vegetasi Rapat & Sawah \\
5 & $0.80-1.00$ & Vegetasi Sangat Rapat & Sawah \\
\hline
\end{tabular}




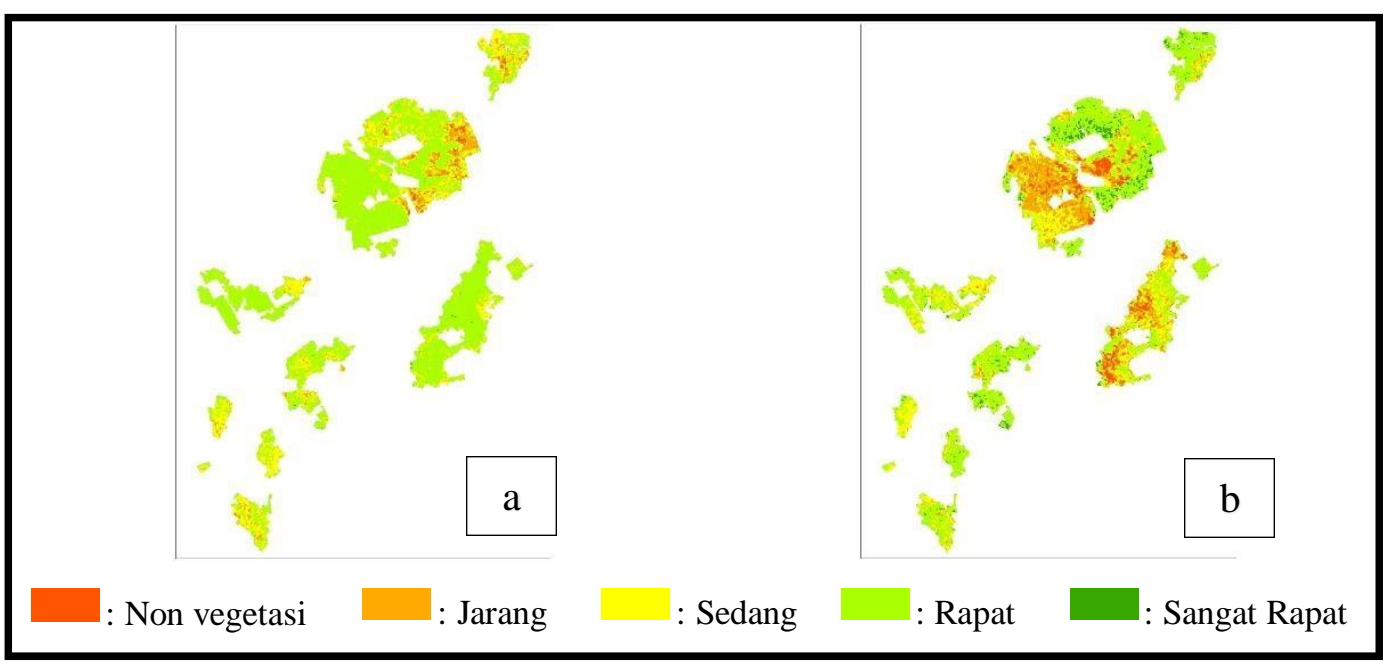

Gambar 8. Sebaran nilai indeks lahan sawah Kabupaten Buru tahun 2020; a) Maret; b) Mei

Tabel 7. Kalender tanam lahan sawah

\begin{tabular}{|c|c|c|c|c|}
\hline \multirow[t]{2}{*}{ Kecamatan } & \multicolumn{2}{|c|}{ Bulan } & \multirow[t]{2}{*}{ Jenis Irigasi } & \multirow[t]{2}{*}{ Kalender Tanam } \\
\hline & Maret & Mei & & \\
\hline \multirow[t]{2}{*}{ Waeapo } & Fase generatif & Fase vegetatif & $\begin{array}{l}\text { Semi Teknik Sederhana, } \\
\text { Tadah Hujan }\end{array}$ & Maret 2020 - Maret 2021 \\
\hline & Fase vegetatif & Fase generatif & & \\
\hline Waelata & Fase generatif & Fase tanam & & \\
\hline \multirow[t]{2}{*}{ Lolong Guba } & Fase tanam & Fase generatif & & \\
\hline & Fase vegetatif & Fase vegetatif & & \\
\hline
\end{tabular}

\section{Kalender Tanam}

Gambar 7 menunjukkan penyebaran nilai NDVI di lahan sawah pada tiga kecamatan di Kabupaten Buru dari tahun 2020. Penyebaran nilai NDVI dikelompokkan dalam warna yang berbeda untuk memberikan informasi yang mudah dipahami. Penyebaran nilai NDVIakan berbeda di setiap citra yang disebabkan oleh fase pertumbuhan tanaman padi yang berbeda antara satu lokasi dengan lokasi lainnya.

\section{Musim Tanam Lahan Sawah}

Berdasarkan fase pertumbuhan tanaman padi yang dianalisis dari citra musim tanam dan hasil pengamatan serta wawancara dengan petani di lahan sawah pada lokasi penelitian, maka diketahui musim tanam padi 2 kali sampai 2.5 kali terjadi di sebagian besar wilayahdi Kabupaten Buru.

Berdasarkan hasil analisis pada citra diketahui jika musim tanam tidak terjadi pada waktu yang sama setiap tahunnya, hal ini dapat diketahui dari visual citra yang menampilkan dominasi warna yang berbeda pada bulan yang sama dan tahun yang berbeda. Berdasarkan hasil wawancara dengan petani di lokasi penelitian, musim tanam pada lahan sawah umumnya tidak bisa ditentukan berdasarkan musim tanam hal ini terjadi karena sebagian besar petani bertanam sesuai dengan ketersediaan air irigasi. Sebagian besar petani di Kabupaten Buru memiliki musim tanam padi 2 kali per tahun atau 5 kali per dua tahun, musim tanam ini tetap berjalan tetapi tidak dapat ditentukan berdasarkan bulan.

Berdasarkan hasil analisis citra terdapat perbedaan antara fase pertumbuhan padi di dalam satu bulan, hal ini dikarenakan waktu tanam yang tidak seragam antara satu petani dengan petani lainnya, atau antara satu desa dengan desa yang lain. Biasanya perbedaan waktu tanam berkisar antara 1-14 hari pada setiap desa. Perbedaan fase pertumbuhan padi pada setiap tahun juga dikarenakan petani yang bertanam sesuai dengan ketersediaan air di lahan.

Hasil wawancara dengan petani dan survei lapangan menunjukkan perbedaan waktu tanam disebabkan oleh beberapa faktor seperti ketersediaan air, mesin pertanian, banjir, umur varietas padi yang digunakan dan juga untuk menjaga kestabilan harga beras di pasaran.

\section{Uji Akurasi}

Untuk mengetahui tingkat akurasi pada citra yang digunakan maka dilakukan uji akurasi atau uji ketelitian. Uji akurasi dilakukan setelah tahap analisis citra satelit dengan tujuan untuk mengetahui tingkat 
akurasi pada citra yang digunakan dalam mengelompokkan objek yang teridentifikasi pada citra dengan kenampakan objek yang sebenarnya di lapangan. Hasil uji akurasi diperoleh dari hasil analisis citra Landsat 8 OLI dengan hasil pengamatan lapangan pada 3 Kecamatan di Kabupaten Buru.

Berdasarkan hasil analisis nilai overall accuracy sebesar 88\%. Menurut Andana (2015) nilai overall accuracy dianggap benar jika nilai overall accuracy di atas batas toleransi yang diberikan yaitu $\geq 80 \%$. Nilai uji ketelitian di lokasi penelitian termasuk dalam kategori sangat kuat (very good) karena nilai Kappa berkisar antara $81 \%$ sampai $100 \%$.

\section{KESIMPULAN}

Dari penelitian yang telah dilaksanakan ini dapat dikemukakan kesimpulan sebagai berikut:

1. Berdasarkan transformasi NDVI yang dilakukan pada citra Landsat 8 OLI tahun perekaman 2020 didapatkan penyebaran nilai indeks vegetasi di lahan sawah Kabupaten Buru yaitu: -1 - 0.15 (Non Vegetasi), 0.15 0.30 (Vegetasi Jarang), 0.30 - 0.55 (Vegetasi Sedang), 0.55 - 0.80 (Vegetasi Rapat) dan 0.80 - 1 (Vegetasi Sangat Rapat). Perbedaan nilai indeks antara satu lokasi dengan lokasi lain dipengaruhi oleh perbedaan waktu tanam ataupun waktu panen padi.

2. Berdasarkan hasil analisis NDVI citra Landsat 8 OLI dan wawancara dengan petani di lapangan, didapatkan musim tanam di lahan sawah Kabupaten Buru bervariasi, dengan musim tanam padi 2 kali per tahun dan padi 5 kali per dua tahun. Musim tanam di lokasi penelitian tidak berulang setiap tahunnya karena waktu tanam padi bisa mengalami kemajuan ataupun kemunduran yang disebabkan oleh ketersediaan air, baik air irigasi maupun curah hujan.

3. Hasil uji akurasi pada citra Landsat 8 OLI yang digunakan dan pengujian di lapangan pada lahan sawah di Kabupaten Buru sebesar 88\%. Nilai Kappa accuracy sebesar $84 \%$ termasuk ke dalam kategori sangat kuat (very good) karena nilai Kappa berkisar antara $81 \%$ sampai $100 \%$.

\section{DAFTAR PUSTAKA}

Ardiansyah, S., Subiyanto dan A. Sukmono. 2015. Identifikasi lahan sawah menggunakan NDVI dan PCA pada citra Landsat 8 (Studi kasus: Kabupaten Demak, Jawa Tengah). Jurnal Geodesi Undip 4(4):316-324.

Avicienna, M., B. Tjahjono dan A. Sutandi. 2012.
Teknik penginderaan jauh untuk pemilihan lahan pertanian padi Sawah berkelanjutan. Jurnal Ilmu Tanah dan Lingkungan 14(2):56-65. DOI: https://doi.org/10.29244/jitl.14.2.56-65

BPS Maluku. 2019. Provinsi Maluku Dalam Angka 2019. Badan Pusat Statistik Provinsi Maluku. Ambon.

Djurdjani dan Kartini. 2004. Pengolahan Citra Digital. Teknik Geodesi Universitas Gadjah Mada. Yogyakarta.

Hafizh, A., A. Cahyono dan A. Wibowo. 2013. Penggunaan algoritma NDVI dan EVI pada citra multispektral untuk analisis pertumbuhan padi: Studi Kasus Kab Indramayu Jawa Barat. Jurnal Geoid 9 (1):7-10. DOI: https://dx.doi.org/10. 12962/j24423998.v9i1.733

Hardjowigeno S, H. Subagyo dan M. Luthf. 2004. Tanah Sawah dan Teknologi Pengelolaannya. Pusat Penelitian Tanah dan Agroklimat. Departemen Pertanian, Bogor.

Loveland, R. dan R. Irons. 2016. Landsat 8: The plans, the reality and the legacy. Remote Sensing of Environment 185:1-6. DOI: 10.1016/j.rse. 2016. 07.033

Makarim, A.K., Ikhwani dan M.J. Mejaya. 2017. Rasionalisasi pola rotasi tanaman pangan berbasis ketersediaan air. Iptek Tanaman Pangan 12(2):83-90.

Murdiyati, S. dan P. Danoedoro. 2010. Integrasi transformasi spektral citra Landsat $\mathrm{ETM}^{+}$dan SIG untuk pemetaan pola rotasi tanam lahan sawah Kabupaten dan Kota Semarang serta daerah sekitarnya di Jawa Tengah. Jurnal Majalah Geografi Indonesia 24(2):121-141. DOI: https: //doi.org/10.22146/mgi.13350

Prasetyo N., B. Sasmito dan Y. Prasetyo. 2017. Analisis perubahan kerapatan hutan menggunakan metode NDVI dan EVI pada citra satelit Landsat 8 tahun 2013 dan 2016: Studi kasus Kabupaten Semarang. Jurnal Geodesi Undip 6(3):21-27

Siahaya, W.A., 2016. Pengaruh perubahan tutupan lahan terhadap perubahan penutup bentik dasar perairan pesisir pulau kecil berdasarkan citra satelit resolusi menengah (Studi kasus empat belas DAS yang bermuara di Teluk Ambon). Disertasi S3, Program Pascasarjana, Universitas Gadjah Mada, Yokyakarta.

Xie, Y., Z. Sha, and M. Yu. 2008. Remote sensing imagery in vegetation mapping: a review. Plant Ecology Jurnal 1(1):9-23. DOI: 10.1093/jpe/ rtm005 